\title{
Developing Strong Teamwork to Support Excellence in Extension Programming ${ }^{1}$
}

\author{
Hannah Carter, Amy Harder, and Kevan Lamm²
}

\section{"Teamwork is the fuel that allows common people to attain uncommon results." - Andrew Carnegie}

Extension has the incredible potential to be composed of highly functioning teams that move the organization forward in a positive and productive manner. You may belong to teams within your county, district, programmatic area, and professional associations, and you may also belong to one or more of the UF/IFAS Extension initiatives and priority workgroups. However, sometimes differentiating a group from a team is difficult. Is the group of people that you work with truly a team? What benefits are there to being a member of a highly functioning team?

Teams are broadly defined as a collection of people coming together to achieve a goal (West, 2004). One of the requirements of teamwork is being dependent upon team members to follow through on responsibilities, work through conflict, be committed to each other and the goal, communicate effectively, and put the needs of the team before the individual needs of team members (Hughes \& Terrell, 2007).

In Patrick Lencioni's iconic book on teamwork, The Five Dysfunctions of a Team (2002), five elements are outlined as necessary for highly functioning teams. These are trust, ability to successfully engage in conflict, commitment to each other and the team, accountability, and focusing on collective results.
"Trust lies at the heart of a functioning, cohesive team. Without it, teamwork is all but impossible" (Lencioni, 2002, p. 195).

How many times have you had to work with someone, or a group of people, that you felt like you couldn't trust? When we are with people we don't think we can trust, we tend to be more guarded and less forthcoming than we would like. Authenticity, transparency, and vulnerability are critical to being the best team member you can be.

\section{"All great relationships, the ones that last over time, require productive conflict in order to grow" (Lencioni, 2002, p. 202).}

Conflict is what strengthens us and our relationships. It also forces us to turn a critical eye to what we are doing and what we have done and ask ourselves, "Is this the best I/we can do?" Sometimes we may find that it is, and sometimes we may find that our views are different from others. Through conflict, we determine how to proceed. Without conflict, we are locked in a holding pattern. The opposite of good is not necessarily bad. It is sometimes irrelevance. Without healthy conflict you may find that your-and the team's-actions are irrelevant.

1. This document is AEC480 (formerly WC143), one of a series of the Agricultural Education and Communication Department, Florida Cooperative Extension Service, Institute of Food and Agricultural Sciences, University of Florida. Original publication date May 2013. Visit the EDIS website at http:// edis.ifas.ufl.edu.

2. Hannah Carter, assistant professor; Amy Harder, associate professor; and Kevan Lamm, doctoral student, Agricultural Education and Communication Department, Florida Cooperative Extension Service, Institute of Food and Agricultural Sciences, University of Florida, Gainesville, FL 32611. 
"In the context of a team, commitment is a function of two things: clarity and buy-in" (Lencioni, 2002, p. 207).

It is fine to disagree. In fact, healthy conflict is a good thing. However, once a decision is made, it is critical that everyone fully support the group decision. To be a highly functioning team, there can't be individuals pushing their own agendas at the expense of the team's performance. Once a decision is made, it is time to move on. You must let a decision succeed or fail on its own merits rather than continually undermining it.

Accountability "in the context of teamwork...refers specifically to the willingness of team members to call their peers on performance or behaviors that might hurt the team" (Lencioni, 2002, p. 212).

This can be extremely uncomfortable depending on your natural predisposition toward interpersonal conflict. However, this does not need to be as stressful as you may think. Rather than viewing it as a personal issue, think of it as a practical issue. For example, if you were taking a taxi to a certain address and the driver mistakenly took you to the wrong place, it would be perfectly acceptable to point out the error. Maybe the driver's intentions were good, but at the end of the day the task was not accomplished correctly. Although interactions on teams are usually not this cut and dry, the premise is the same-we are in this together and if we are headed in the wrong direction, it does not benefit anyone.

\section{"The ultimate dysfunction of a team is the tendency of members to care about something other than the collec- tive goals of the group" (Lencioni, 2002, p. 216).}

While there is a significant amount of overlap between these dysfunctions, hopefully it is clear why this is a unique dysfunction of its own. This can be one of the most destructive acts on a team. While the intent might not be malicious, it is harmful all the same. With limited time and resources, it is important to get the most out of everyone. If someone is actively working to pursue their own motivesand those motives are not aligned with the group goal-it can actually hurt the team.

Highly functioning teams can work together in the following ways to achieve excellence in Extension:

1. Choose to work with individuals you trust. Trust your teammates to provide you with honest but constructive feedback on your ideas, meet deadlines, provide help when needed, and conduct programming and evaluation in an ethical manner. Trust is the foundation on which successful teams are built.

2. Embrace conflict as the process by which good products become great. Team members often have different ideas about the direction that a program should take, including which needs are truly priorities, which stakeholders should be targeted, and which educational outcomes are most important. This can be particularly difficult when working on a team designed to develop a plan for the "big picture" versus those working on more localized plans. Conflict that is addressed maturely within the team will result in an improved final product (e.g., a program plan) and a team that's better able to solve problems in the future.

3. Develop one or more clear goals for the programming your team wants to conduct. Why are the proposal goals critical? How do they compare with any alternatives being suggested? When everyone understands what the goal is and why, it's much easier for team members to commit to moving confidently ahead, even if they aren't in complete agreement.

4. Establish critical elements of the program that are mandatory for everyone and hold each other accountable for following through. This might mean that everyone commits to expanding their volunteer base, recruiting more diverse clientele, or agreeing to use the same evaluation methods. Holding each other accountable to high standards inspires people to improve and establishes respect among the team.

5. Believe that your program will achieve excellence! Your team should share in this belief and not be willing to accept any other alternative. This mindset will help your team to move forward when encountering setbacks, such as fluctuations in resources. The team should commit to overcoming them to realize the ultimate goal.

Remember these elements when building teams within Extension. If one or more are missing, spend the time to work through the issues. While it may be uncomfortable and take time, the benefits in the end are well worth it!

\section{References}

Hughes, M., \& Terrell, J. B. (2007). The emotionally intelligent team. San Francisco, CA: Jossey-Bass.

Lencioni, P. (2002). The five dysfunctions of a team. San Francisco, CA: Jossey-Bass.

West, M. A. (2004). Effective teamwork. Malden, MA: Blackwell. 